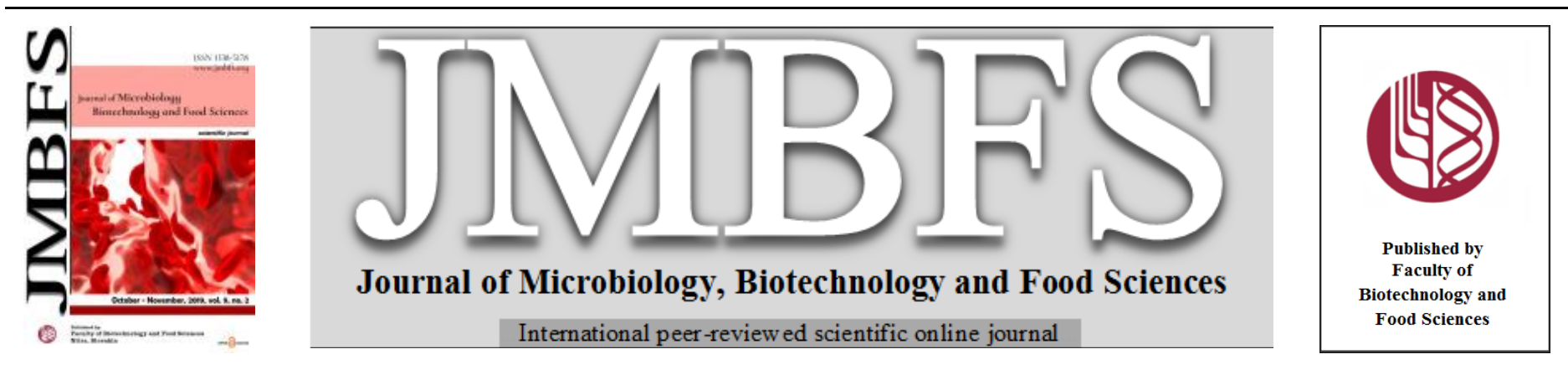

\title{
GENOMIC FINGERPRINTS OF ARACHIS HYPOGAEA L. NATURAL GERMPLASM AS REVEALED BY IPBS MARKERS
}

\section{Julio Montero-Torres ${ }^{1}$, Lucia Zamiešková ${ }^{2}$, Tania Pozzo ${ }^{3}$,Eloy Fernández ${ }^{4}$, Sandra Romero-Ortega ${ }^{1}$, Jana Bezáková ${ }^{5}, J_{a n a}$ Žiarovská*2}

Address(es):

${ }^{1}$ Major, Real and Pontifical University of San Francisco Xavier in Chuquisaca, Faculty of Agricultural Sciences, Germplasm Bank - BIORENA, Calvo Street No. 132, Sucre, Bolivia.

${ }^{2}$ Slovak University of Agriculture in Nitra, Faculty of Agrobiology and Food Resources, Department of Genetics and Plant Breeding, Tr. A. Hlinku 2, 94976, Nitra, Slovak Republic.

${ }^{3}$ University of California, Department of Plant Sciences, Davis, California 95616, United States of America.

${ }^{4}$ Czech University of Life Sciences Prague, Faculty of Tropical AgriSciences, Department of Crop Sciences and Agroforestry, Kamýcká 129, 165 21, Prague 6, Czech Republic.

${ }^{5}$ Slovak University of Agriculture in Nitra, Research Centre of AgroBioTech, Tr. A. Hlinku 2, 94976, Nitra, Slovak Republic.

*Corresponding author: jana.ziarovska@uniag.sk

doi: $10.15414 / j m b f s .2020 .9 .5 .955-959$

\section{ARTICLE INFO}

Received 23. 5. 2019

Revised 12. 11. 2019

Accepted 15. 11. 2019

Published 1. 4. 2020

Regular article OPEN $\partial$ ACCESS

\begin{abstract}
Arachis hypogaea, $\mathrm{L}$. is an oil seed crop with a worldwide importance and the seeds are eaten at one of several stages from immature to fully ripe, raw, or cooked. The aim of the study was to analyze specific iPBS fingerprints of twenty-one accessions of peanut that were collected in the places of their natural occurrence in Bolivia and describe the existing genetic polymorphism. For genomic imprinting, three different iPBS markers were chosen - 1882, 2079, 2274 and a PCR reactions were performed. Obtained iPBS fingerprints were evaluated for the presence/absence of individual amplified loci and scored in 1/0 matrices. A Jaccard coefficient of genetic similarity was applied in UPGMA analysis for dendrogram construction. Polymorphism level was achieved in the range from $48 \%$ up to the $75 \%$ per primer. None of the iPBS markers used in the study was considered to distinguish all of the analyzed peanut accessions, but combining them in the final analysis, the level of genomic polymorphism was sufficient to clear separating of iPBS fingerprints of the collected accessions and unique iPBS loci were recorded in genomes of some of them. We found that, by selecting the appropriate iPBS markers, it is possible to characterize the peanut genome in the individual level with a specific fingerprint.
\end{abstract}

\section{INTRODUCTION}

Arachis hypogaea, L. is a world known oil seed crop that is harvested mainly in semi-arid tropical, subtropical and temperate regions (Naidu et al., 1999; Proite et al., 2007). The earliest archeological reports of peanut comes from Peru and dates back to 3900-3750 years ago (Hammons, 1994). The genus Arachis originated in the southwestern part of Mato Grosso do Sul, Brazil, or northeast Paraguay (Simpson et al., 2001). Arachis contains 81 described species that have been classified in nine distinct taxonomic sections based on cross-compatibility, morphological characters, and geographic origin (Krapovickas and Gregory, 1994; Valls and Simpson, 2005).The cultivated form of peanut originated in the area of southern Bolivia to the northwestern Argentina, where the great range of ecologically distinctive environments exist in the Andes eastern foothills (Stalker and Simpson, 1995). The diversity of uses of peanuts is an evidence of its antiquity - the seeds are eaten at one of several stages from immature to fully ripe, raw, or cooked. They are processing by boiling, broiling, roasting, crushing or grounding and mixing with other food.

The whole young pods are occasionally used in soups after boiling, peanuts are further used to make a beer and a nonalcoholic drink. The oil is also processed into soap (Stalker and Wilson, 2016). Arachis hypogaea is an allotetraploid species $(2 \mathrm{n}=4 \mathrm{x}=40, \mathrm{AABB})$ with a very large and complex genome. Cytological, it behaves mostly as a diploid, but multivalents can result in skewed genetic ratios and likely account for many of the "off types" (Leal-Bertioli et al., 2015).

Because of economic importance of cultivated peanut, its germplasm is preserved and maintained around the world in different ex situ collections (Benz, 2012). The largest collections of Arachis germplasm are in India (International Crops Research Institute for the Semi-Arid Tropics), United States (United States Department of Agriculture), China (Oil Crops Research Institute, Chinese
Academy of Agricultural Sciences), and Brazil (Empresa Brasileira de Pesquisa Agropecuaria), and smaller collections do exist in many countries around the world (Richards and Volk, 2010).

Many different techniques are applied to describe and characterize plant genetic resources. One of the most modern are those based on DNA markers. Different specific regions of plant genomes are used as DNA markers and many of different techniques were applied successfully for a wide range of plants, such as SCoT markers for cultivated castor (Vivodik et al., 2019), SSR markers for triticale (Balážová et al., 2016), RAPD markers for wheat (Kut'ka-Hlozáková et al., 2016), or iPBS markers for common ivy (Žiarovská et al., 2019). In the case of peanut, DNA markers were used to analyse different questions connected to its genome variability. Microsatellite markers were applied to analyse cultivated peanuts by $\mathrm{He}$ et $\boldsymbol{a l}$. (2005) and test its transferability to analyze peanuts by Gimenes et al. (2007), specific SSR markers were isolated (Cuc et al., 2008) and developed from the EST sequencing by Song $\boldsymbol{e t}$ al. (2010), intron sequences and microsatellite markers were used for the purpose of molecular breeding (Pandey et al., 2012) and study of phylogenetic relationships of peanut by Moretzsohn et al. (2013). Amplified fragment length polymorphism (AFLP) markers were applied in the studies of identification of polymorphic regions of peanut genomes by $\mathrm{He}$ and Prakash (1997, 2001). Random amplified polymorphism detection (RAPD) fingerprints were defined for Arachis hypogaea, L. genome by Raina et al. (2001) and used to link some important resistance genes (Mondal et al., 2007).

Here, iPBS markers were used to analyze the genome diversity of natural accessions of peanut. Up to now, this markers were not used for the analysis of Arachis hypogaea, L.. iPBS markers were developed based on the specific sequential characteristics of primer binding sites typical for retrotransposon elements by Kalendar et al. (2010). Retrotransposons are an abundant and natural part of plant genomes and have some specificities that allow to use them 
as universal marker systems without a previous knowledge about a very concrete retrotransposons that are presented in the genome of a specie of interest. Moreover, retrotransposons are well known as markers revealing insertion fingerprints based on different biotic or abiotic stress history of plant genomes (Kalendar et al., 2010), what makes them a very good marker system when analyzing natural plant populations. This marker technique provide repeatable, time efficient and universal approach, that can be used for fingerprint profiling. They were used in genome polymorphism analysis in many plant species such as Cicer spp. (Andeden et al., 2013), Adonis spp., Paeonia anomala L., Adenophora lilifolia (L.)A.DC. and Digitalis grandifolia Mill. (Boronnikova and Kalendar, 2010), Fagaceae species (Coutinho et al., 2018), Vitis vinifera L. (Gou et al., 2014; Milovanov et al., 2019). They are also applied in high-throughput sequencing for the development of new types of retrotransposon-based markers (Monden et al., 2014).

The objective of our study was to analyze specific iPBS fingerprints of twenty one accessions of Arachis hypoaea, L. that were collected in the places of their natural occurrence in Bolivia and describe the existing genetic polymorphism.

\section{MATERIAL AND METHODS}

\section{Plant material}

Twenty one different accessions of peanut germplasm seeds have been taken in Chuquisaca Department, Bolivia as original plant sources. The seeds were transferred to the Faculty of Tropical Agriculture, Czech University of Life Sciences in Prague; Czech Republic and planted in pots. Young plants were transferred to the Research center AgroBioTech; Slovak University of Agriculture in Nitra, Slovak Republic where biological material was processed and stored at $-50^{\circ} \mathrm{C}$ until DNA extraction.

\section{Total genomic DNA extraction}

Total genomic DNA was extracted from collected leaves (5 for each plant) using a GeneJET Plant Genomic DNA Purification Mini Kit ThermoScientific) and following the manufacturer's instructions. Concentration and purity of extracted DNA was measured by NanoPhotometer ${ }^{\circledR}$ P-Class by Implen and checked in $1 \%$ agarose gel electrophoresis.

\section{PCR and iPBS reaction performing}

DNA from all samples was mixed firstly by $1 \mu \mathrm{L}$ per accessions and the resulted solution was diluted to three concentrations: 1:10, 1:25 and 1:50. Mixed DNAs was used in the polymerase chain reaction with 10 randomly selected iPBS primers $(1830,1845,1846,1881,1882,1886,1897,2079,2274$ and 2392) (Kalendar et al., 2010) and based on the screening, three of them were used further in the analysis. It was conducted in $10 \mu \mathrm{L}$ volume. Amplification were performed by Agilent Technologies SureCycler 8800 using $2 \mathrm{X}$ EliZyme HS Robust MIX (MasterMix). PCR program setup: initial denaturation $95^{\circ} \mathrm{C}$ for 3 min, followed by 35 cycles of $95^{\circ} \mathrm{C}$ for $30 \mathrm{~s}, 55^{\circ} \mathrm{C}$ for $40 \mathrm{~s}, 72^{\circ} \mathrm{C}$ for $2 \mathrm{~min}$ and final extension at $72^{\circ} \mathrm{C}$ for $5 \mathrm{~min}$. Based on the preliminary results, primers 1882, 2079, 2274 were selected (1:25 DNA dilution) for iPBS analysis of peanut varieties. The same PCR mix and PCR program were used to amplify iPBS profiles.

\section{Data processing}

Electrophoresis was performed in 3\% agarose gel stained with GelRed in 1X TBE buffer for initial screening PCR reactions. Samples were stained with
GelRed (Biotia), loaded on gel, and photographed under ultraviolet light by UV and white light transilluminator UVstar, Biometra, wavelength $312 \mathrm{~nm}$. For iPBS amplicons processing, electrophoresis was done on $10 \%$ PAGE in a $5 \mathrm{X}$ TBE buffer. The gel was stained in $5 \mathrm{X}$ TBE mixed with GelRed for 1 hour and photographed under ultraviolet light by UV and white light transilluminator UVstar, Biometra, wavelength $312 \mathrm{~nm}$.

Obtained iPBS fingerprints were evaluated for the presence/absence of individual loci and scored in 1/0 matrices. A Jaccard coefficient of genetic similarity (Jaccard, 1908) was applied in UPGMA analysis for dendrograms construction. Cophenetic coefficients (Lessig, 1972) were calculated for dendrograms and polymorphic information content coefficients (PIC) (Weber, 1990) for individua iPBS primers used in the study. Dendrograms were constructed by SYNTAX software.

\section{RESULTS AND DISCUSSION}

The iPBS markers has been proved to be a powerful DNA fingerprinting technology. This method is used for investigation of new long terminal repeats type of retrotransposons in any eukaryotic organism. It was reported that primers that are designed to hybridize the conserved regions of the primer binding sequences of retrotransposons, are very efective in PCR amplification (FangYong and Ji-Hong 2014; Kalendar et al. 2019). This method can differentiated close genotypes (Antonius-Klemola et al., 2006) and it can be used without prior genome sequence knowledge, is highly reproducible and has high stringency (Guo et al. 2014; Antonius-Klemola et al. 2006). This method can be applied not only to endogenous retroviruses, but also for both the Gypsy and Copia LTR retrotransposons, too (Melnikova et al. 2012).

Inter primer binding sites polymorphism was analyzed in the study for the peanut accessions. All of the iPBS markers that were used in the study, generated a sufficient amount of amplicons, but the variability in achieved percentage of polymorphism (table 1)

Table 1 Characteristics of the iPBS fingerprints used for peanut germplasm analysis

\begin{tabular}{lcccc}
\hline $\begin{array}{l}\text { iPBS } \\
\text { marker }\end{array}$ & $\begin{array}{c}\text { Number of } \\
\text { fragments }\end{array}$ & $\begin{array}{c}\text { \% of } \\
\text { polymorphism }\end{array}$ & PIC & $\begin{array}{c}\text { Cophenetic } \\
\text { coefficient in } \\
\text { UPGMA }\end{array}$ \\
\hline 1882 & 70 & 48 & 0.43 & 0.89 \\
2079 & 168 & 67 & 0.46 & 0.83 \\
2274 & 205 & 75 & 0.33 & 0.91 \\
\hline
\end{tabular}

Amplification of retrotransposon insertion loci by iPBS marker 1882 resulted in seven different locus levels with the obtained low polymorphism at the level of $48 \%$. This marker provided the lowest amount of amplicons (table 1) per accessions with the maximum of 5 and minimum of 2 generated amplicons with the length varied from 200 up to the 750 base pairs. Dendrogram constructed from 1882 marker generated data has grouped the peanut accessions into two main clusters with a very different iPBS profile for accession no. 20 that was separated from the other accessions at the level of UPGMA dissimilarity of 0.55 (dendrogram not shown). The Jaccard coefficient of genetics dissimilarity has ranged from 0.00 up to the 0.71 . When analyzed the peanut germplasm collection by iPBS marker 1882, eighteen from the accession was not possible to separate based on the obtained iPBS fingerprints. These were grouped into five alone standing sub clusters with the following group distribution of accessions $(1,13,14,15) ;(7,16) ;(2,3,5,6,8,11,12,17) ;(4,21)$ and $(9,18)-$ all of these possess the Jaccard coefficient of genetic dissimilarity 0.00 (figure 1).

\begin{tabular}{|c|c|c|c|c|c|c|c|c|c|c|c|c|c|c|c|c|c|c|c|c|c|}
\hline & 1 & 2 & 3 & 4 & 5 & 6 & 7 & 8 & 9 & 10 & 11 & 12 & 13 & 14 & 15 & 16 & 17 & 18 & 19 & 20 & 21 \\
\hline 1 & 0.00 & & & & & & & & & & & & & & & & & & & & \\
\hline 2 & 0.33 & 0.00 & & & & & & & & & & & & & & & & & & & \\
\hline 3 & 0.33 & 0.00 & 0.00 & & & & & & & & & & & & & & & & & & \\
\hline 4 & 0.50 & 0.25 & 0.25 & 0.00 & & & & & & & & & & & & & & & & & \\
\hline 5 & 0.33 & 0.00 & 0.00 & 0.25 & 0.00 & & & & & & & & & & & & & & & & \\
\hline 6 & 0.33 & 0.00 & 0.00 & 0.25 & 0.00 & 0.00 & & & & & & & & & & & & & & & \\
\hline 7 & 0.33 & 0.50 & 0.50 & 0.25 & 0.50 & 0.50 & 0.00 & & & & & & & & & & & & & & \\
\hline 8 & 0.33 & 0.00 & 0.00 & 0.25 & 0.00 & 0.00 & 0.50 & 0.00 & & & & & & & & & & & & & \\
\hline 9 & 0.60 & 0.40 & 0.40 & 0.20 & 0.40 & 0.40 & 0.40 & 0.40 & 0.00 & & & & & & & & & & & & \\
\hline 10 & 0.50 & 0.25 & 0.25 & 0.40 & 0.25 & 0.25 & 0.60 & 0.25 & 0.50 & 0.00 & & & & & & & & & & & \\
\hline 11 & 0.33 & 0.00 & 0.00 & 0.25 & 0.00 & 0.00 & 0.50 & 0.00 & 0.40 & 0.25 & 0.00 & & & & & & & & & & \\
\hline 12 & 0.33 & 0.00 & 0.00 & 0.25 & 0.00 & 0.00 & 0.50 & 0.00 & 0.40 & 0.25 & 0.00 & 0.00 & & & & & & & & & \\
\hline 13 & 0.00 & 0.33 & 0.33 & 0.50 & 0.33 & 0.33 & 0.33 & 0.33 & 0.60 & 0.50 & 0.33 & 0.33 & 0.00 & & & & & & & & \\
\hline 14 & 0.00 & 0.33 & 0.33 & 0.50 & 0.33 & 0.33 & 0.33 & 0.33 & 0.60 & 0.50 & 0.33 & 0.33 & 0.00 & 0.00 & & & & & & & \\
\hline 15 & 0.00 & 0.33 & 0.33 & 0.50 & 0.33 & 0.33 & 0.33 & 0.33 & 0.60 & 0.50 & 0.33 & 0.33 & 0.00 & 0.00 & 0.00 & & & & & & \\
\hline 16 & 0.33 & 0.50 & 0.50 & 0.25 & 0.50 & 0.50 & 0.00 & 0.50 & 0.40 & 0.60 & 0.50 & 0.50 & 0.33 & 0.33 & 0.33 & 0.00 & & & & & \\
\hline 17 & 0.33 & 0.00 & 0.00 & 0.25 & 0.00 & 0.00 & 0.50 & 0.00 & 0.40 & 0.25 & 0.00 & 0.00 & 0.33 & 0.33 & 0.33 & 0.50 & 0.00 & & & & \\
\hline 18 & 0.60 & 0.40 & 0.40 & 0.20 & 0.40 & 0.40 & 0.40 & 0.40 & 0.00 & 0.50 & 0.40 & 0.40 & 0.60 & 0.60 & 0.60 & 0.40 & 0.40 & 0.00 & & & \\
\hline 19 & 0.60 & 0.40 & 0.40 & 0.20 & 0.40 & 0.40 & 0.40 & 0.40 & 0.33 & 0.50 & 0.40 & 0.40 & 0.60 & 0.60 & 0.60 & 0.40 & 0.40 & 0.33 & 0.00 & & \\
\hline 20 & 0.60 & 0.66 & 0.66 & 0.50 & 0.66 & 0.66 & 0.40 & 0.66 & 0.33 & 0.71 & 0.66 & 0.66 & 0.60 & 0.60 & 0.60 & 0.40 & 0.66 & 0.33 & 0.33 & 0.00 & \\
\hline 21 & 0.50 & 0.25 & 0.25 & 0.00 & 0.25 & 0.25 & 0.25 & 0.25 & 0.20 & 0.40 & 0.25 & 0.25 & 0.50 & 0.50 & 0.50 & 0.25 & 0.25 & 0.20 & 0.20 & 0.50 & 0.0 \\
\hline
\end{tabular}

Figure 1 Jaccard coefficient values in the analyzed peanut germplasm accessions by iPBS marker 1882

Amplification of retrotransposon insertion loci by iPBS marker 2079 resulted in twelve different locus levels with the obtained polymorphism at the level of 67

$\%$. This marker provided the amount of amplicons (table 1) per accessions with the maximum of 10 and minimum of 6 generated amplicons with the length varied from 100 up to the 800 base pairs. Dendrogram constructed from 2079 marker generated data has grouped the peanut accessions into three main clusters 
(dendrogram not shown). In this case, no very different iPBS fingerprint profile was generated for none of the analyzed accessions. All the generated clusters were joined at the level of UPGMA dissimilarity of 0.4 . The Jaccard coefficien of genetics dissimilarity has ranged from 0.00 up to the 0.54 (figure 2). In the case of this marker, only eight from the accession was not possible to separate based on the obtained iPBS fingerprints. These were grouped into four alone standing sub clusters with the following group distribution of accessions $-(1,8)$; $(4,5) ;(6,17)$ and $(18,19)$

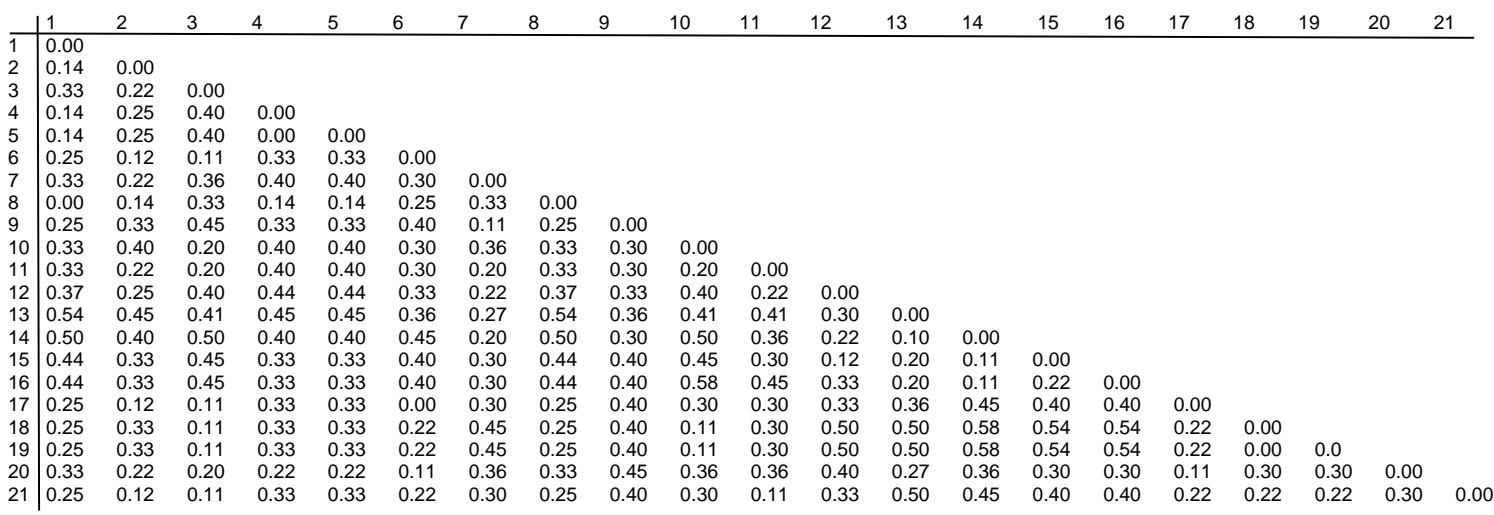

Figure 2. Jaccard coefficient values in the analyzed peanut germplasm accessions by iPBS marker 2079

Amplification of retrotransposon insertion loci by iPBS marker 2274 resulted in thirteen different locus levels with the obtained polymorphism at the level of 67 $\%$. This marker provided the amount of amplicons (table 1) per accessions with the maximum of 12 and minimum of 6 generated amplicons with the length varied from 100 up to the 800 base pairs (figure 3). Dendrogram constructed from 2274 primer generated data has grouped the peanut accessions into three main clusters, but the level of UPGMA dissimilarity, that was lowest from all of the three used iPBS markers. In this case, two accessions $(1,12)$ generated very different iPBS fingerprint profile that separated them from all of the others at the level of 0.24. All the generated clusters were joined at the level of UPGMA dissimilarity of 0.4 . The Jaccard coefficient of genetics dissimilarity has ranged from 0.00 up to the 0.5 (figure 4). In the case of this marker, sixteen of analyzed accessions was not possible to separate based on the obtained iPBS fingerprint (dendrogram not shown). These were grouped into five alone standing sub clusters with the following group distribution of accessions - $(1,12)$ $(2,9,10,11,14,16) ;(13,17) ;(18,19)$ and $(4,7,8,15)$.

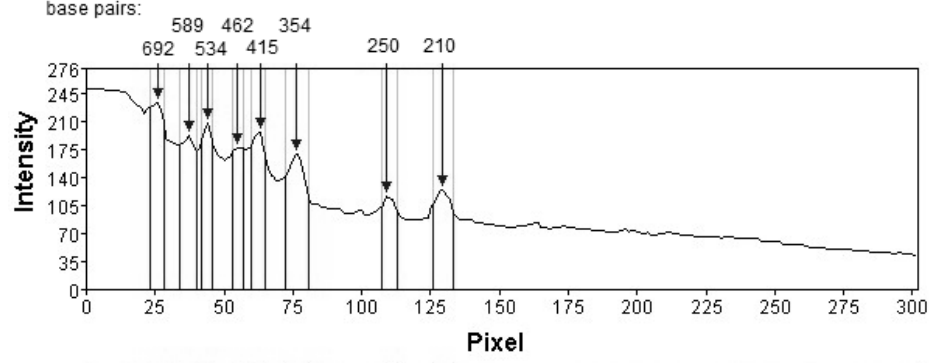

Figure 3 iPBS profile of accession 5 of peanut when iPBS marker 2274 used.

\begin{tabular}{|c|c|c|c|c|c|c|c|c|c|c|c|c|c|c|c|c|c|c|c|c|c|}
\hline & 1 & 2 & 3 & 4 & 5 & 6 & 7 & 8 & 9 & 10 & 11 & 12 & 13 & 14 & 15 & 16 & 17 & 18 & 19 & 20 & 21 \\
\hline 1 & 0.00 & & & & & & & & & & & & & & & & & & & & \\
\hline 2 & 0.45 & 0.00 & & & & & & & & & & & & & & & & & & & \\
\hline 3 & 0.33 & 0.18 & 0.00 & & & & & & & & & & & & & & & & & & \\
\hline 4 & 0.33 & 0.18 & 0.20 & 0.00 & & & & & & & & & & & & & & & & & \\
\hline 5 & 0.40 & 0.25 & 0.27 & 0.10 & 0.00 & & & & & & & & & & & & & & & & \\
\hline 6 & 0.40 & 0.09 & 0.10 & 0.10 & 0.18 & 0.00 & & & & & & & & & & & & & & & \\
\hline 7 & 0.33 & 0.18 & 0.20 & 0.00 & 0.10 & 0.10 & 0.00 & & & & & & & & & & & & & & \\
\hline 8 & 0.33 & 0.18 & 0.20 & 0.00 & 0.10 & 0.10 & 0.00 & 0.00 & & & & & & & & & & & & & \\
\hline 9 & 0.45 & 0.00 & 0.18 & 0.18 & 0.25 & 0.09 & 0.18 & 0.18 & 0.00 & & & & & & & & & & & & \\
\hline 10 & 0.45 & 0.00 & 0.18 & 0.18 & 0.25 & 0.09 & 0.18 & 0.18 & 0.00 & 0.00 & & & & & & & & & & & \\
\hline 11 & 0.45 & 0.00 & 0.18 & 0.18 & 0.25 & 0.09 & 0.18 & 0.18 & 0.00 & 0.00 & 0.00 & & & & & & & & & & \\
\hline 12 & 0.00 & 0.45 & 0.33 & 0.33 & 0.40 & 0.40 & 0.33 & 0.33 & 0.45 & 0.45 & 0.45 & 0.00 & & & & & & & & & \\
\hline 13 & 0.40 & 0.09 & 0.10 & 0.27 & 0.33 & 0.18 & 0.27 & 0.27 & 0.09 & 0.09 & 0.09 & 0.40 & 0.00 & & & & & & & & \\
\hline 14 & 0.45 & 0.00 & 0.18 & 0.18 & 0.25 & 0.09 & 0.18 & 0.18 & 0.00 & 0.00 & 0.00 & 0.45 & 0.09 & 0.00 & & & & & & & \\
\hline 15 & 0.33 & 0.18 & 0.20 & 0.00 & 0.10 & 0.10 & 0.00 & 0.00 & 0.18 & 0.18 & 0.18 & 0.33 & 0.27 & 0.18 & 0.00 & & & & & & \\
\hline 16 & 0.45 & 0.00 & 0.18 & 0.18 & 0.25 & 0.09 & 0.18 & 0.18 & 0.00 & 0.00 & 0.00 & 0.45 & 0.09 & 0.00 & 0.18 & 0.00 & & & & & \\
\hline 17 & 0.40 & 0.09 & 0.10 & 0.27 & 0.33 & 0.18 & 0.27 & 0.27 & 0.09 & 0.09 & 0.09 & 0.40 & 0.00 & 0.09 & 0.27 & 0.09 & 0.00 & & & & \\
\hline 18 & 0.45 & 0.16 & 0.18 & 0.33 & 0.38 & 0.25 & 0.33 & 0.33 & 0.17 & 0.17 & 0.17 & 0.45 & 0.09 & 0.17 & 0.33 & 0.16 & 0.09 & 0.00 & & & \\
\hline 19 & 0.45 & 0.16 & 0.18 & 0.33 & 0.38 & 0.25 & 0.33 & 0.33 & 0.17 & 0.17 & 0.17 & 0.45 & 0.09 & 0.17 & 0.33 & 0.17 & 0.09 & 0.00 & 0.00 & & \\
\hline 20 & 0.25 & 0.27 & 0.11 & 0.11 & 0.20 & 0.20 & 0.11 & 0.11 & 0.27 & 0.27 & 0.27 & 0.25 & 0.20 & 0.27 & 0.11 & 0.27 & 0.20 & 0.27 & 0.27 & 0.00 & \\
\hline 21 & 0.50 & 0.08 & 0.25 & 0.25 & 0.31 & 0.17 & 0.25 & 0.25 & 0.08 & 0.08 & 0.08 & 0.50 & 0.17 & 0.08 & 0.25 & 0.08 & 0.17 & 0.08 & 0.08 & 0.33 & 0.0 \\
\hline
\end{tabular}

Figure 4 Jaccard coefficient values in the analysed peanut germplasm accessions by iPBS marker 2274

For all of the primer-individual constructed dendrogram, a very high cophenetic coefficients were achieved (table 1) but, the low polymorphic information content values. We suppose, that this is a result of a quite conserved insertions of individual retrotransposon families in the genome of Arachis hypogaea, L. Nascimento et al (2018) has analysed the distribution of LTR segments of retrotransposons in the genome of peanut with the result of the dispersion mainly on arms and proximal regions of most of the chromosomes of Arachis hypogaea, L.. Up to now, sequences of retrotransposons Fidel (Nielen et al., 2010), Feral, Pipa and Pipoka were extracted from the BAC clones of peanut genome. All of them are presented as complete or in a manner of numerous isolated LTRs of these autonomous Ty3-gypsy type elements (Bertioli et al., 2013). Other Ty-3 gypsy elements that were described in the genome of Arachis hypogaea, L. are sequences of Curu, RE138, Grilo, and Mico (Nielen et al., 2010, 2011).

iPBS sequences that were used as markers, were reported previously to be a part of different plant species such as Solanum tuberosum, Brassica rapa, Peonia anomala or Digitalis grandiflora (Kalendar et al., 2010). A complete sequence identity of 1882 primer exist with Linum usitatissimum LTR retrotransposon FL7 (Smýkal et al., 2011).

In order to further evaluate the performance of the iPBS markers and assess the genetic diversities among the varieties, the parameters of polymorphic information content (PIC) was calculated. This value is used to estimate the discriminating ability of a primer and is based on measurements of the efficiency of polymorphic loci in revealing genetic diversity among the varieties (Guo et al., 2014). In this study, the value of PIC ranged from 0.33 to 0.46 (table 1), indicating that the iPBS markers are useful for evaluation of genetic variation of Arachis hypogaea L., because PIC for dominant markers is a maximum of 0.5 (De Riek et al., 2001).

When comparing all of the primer-unique dendrograms generated for analysed peanut germplasm, five of the accession $(1,4,8,9,11$ and 18) where not distinguishable by any of the primers used in the study, but when all the obtained iPBS amplicons were combined together, all of them are clearly separated in the resulted dendrogram (figure 5). 


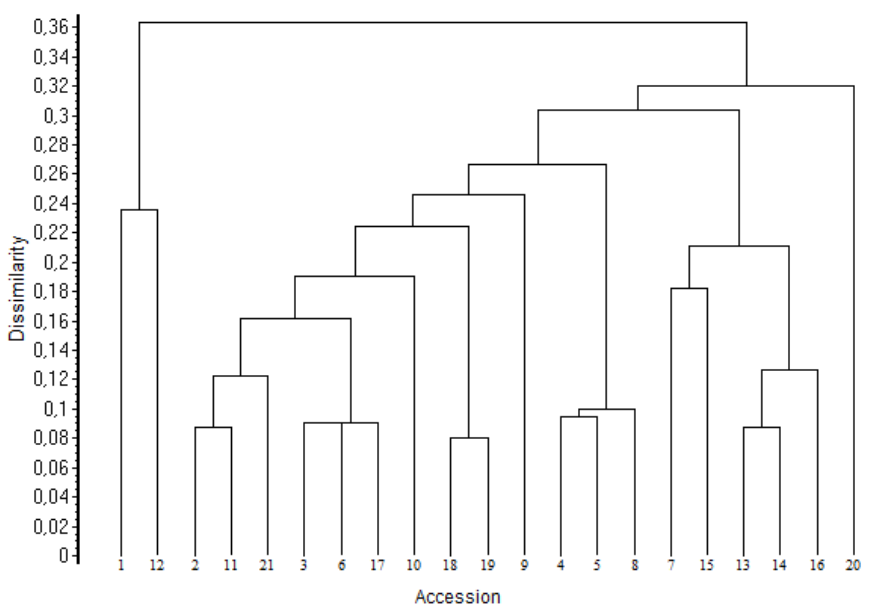

Figure 5 Dendrogram of analysed peanut accessions by combined iPBS generated fingerprints.

\section{CONCLUSION}

We have characterized the genomic iPBS fingerprint polymorphism in group of 21 peanut genotypes that were collected in situ. The analysis showed that the iPBS markers are an easy applicable and effective DNA based markers for the assesment of the genetic diversity in peanut natural germplasm. The dendrograms constructed on UPGMA algorithm divided 21 analyzed accessions into two main clusters in the case of individually evaluated primers used in the study and into a six balances clusters in the case of combining the results of individual primers Using three iPBS primers, some of the peanuts accessions have not been differentiated for individual markers used, but the combined data differentiated all of the analysed accessions. This study consider iPBS markers as sufficiently polymorphic in the genome of peanut that will be useful in the assessment of its diversity and germplasm management for use in breeding and conservation.

Acknowledgments: This work was funded by European Community under project No. 26220220180: Building Research Centre „AgroBioTech”.

\section{REFERENCES}

Andeden, E.E., Baloch, F.S., Kilian, B., Özkan, H. (2013). iPBS-retrotransposons based genetic diversity and relationship among wild annual Cicer species. $J$. Plant Biochem. Biotechnol. 22(4), 453-466. http://dx.doi.org/10.1007/s13562 012-0175-5

Antonius-Klemola, K., Kalendar, R., Schulman, A.H. (2006). TRIM retrotransposons occur in apple and are polymorphic between varieties but not sports. Theoretical and Applied Genetics, 112(6), 999-1008. https://doi.org/10.1007/s00122-005-0203-0

Balážová, Ž., Gálová, Z., Vivodík, M. (2016). Application of rye SSR markers for detection of genetic diversity in triticale. Journal of Microbiology, Biotechnology and Food Sciences , 5(6), 623-626. https://doi.org/10.15414/jmbfs.2016.5.6.623-626

Benz, B. (2012). The conservation of cultivated plants. Natural Education Knowledge, 3(10), 4.

Bertioli, D.J., Vidigal, B., Nielen, S., Ratnaparkhe, M.B., Lee, T.H., LealBertioli, S.C.M., Kim, C., Guimarães, P.M., Seijo, G., Schwarzacher, T., Paterson, A.H., Heslop-Harrison, P., Araujo, A.C.G. (2013). The repetitive component of the A genome of peanut (Arachis hypogaea) and its role in remodelling intergenic sequence space since its evolutionary divergence from the B genome. Annals of Botany, 112(3), 545-559. https://doi.org/10.1093/aob/mct128

Boronnikova, S.V., Kalendar, R.N. (2010). Using IRAP markers for analysis of genetic variability in populations of resource and rare species of plants. Russian Journal of Genetics, 46(1), 36-42. https://doi.org/10.1134/S1022795410010060 Coutinho, J.P., Carvalho, A., Martín, A. Lima-Brito, J. (2018). Molecular characterization of Fagaceae species using inter-primer binding site (iPBS) markers. Molecular Biology Reports, 45(2), 133-142. https://doi.org/10.1007/s11033-018-4146-3

Cuc, L.M., Mace, E.S., Crouch, J.H., Quang, V.D., Long, T.D., Varshney, R.V (2008). Isolation and characterization of novel microsatellite markers and their application for diversity assessment in cultivated groundnut (Arachis hypogaea). BMC Plant Biology, 8(1), 55. https://doi.org/10.1186/1471-2229-8-55

De Riek, J., Calsyn, E., Everaert, I., Van Bockstaele, E., De Loose, M. (2001) AFLP based alternatives for the assessment of distinctness, uniformity and stability of sugar beet varieties. Theoretical and Applied Genetics, 103, 12541265. https://doi.org/10.1007/s001220100710

Fang-Yong, C., Ji-Hong, L. (2014). Germplasm genetic diversity of Myrica rubra in Zhejiang Province studied using inter-primer binding site and start codon- targeted polymorphism markers. Scientia Horticulturae, 170, 169-175 https://doi.org/10.1016/j.scienta.2014.03.010

Gimenes, M.A., Hoshino, A.A., Barbosa, A.V.G., Palmieri, D.A., Lopes, R.L. (2007). Characterization and transferability of microsatellite markers of the cultivated peanut (Arachis hypogaea). BMC Plant Biology, 7(1), 9. https://doi.org/10.1186/1471-2229-7-9

Guo, D.L., Guo, M.X., Hou, X.G., Zhang, G.H. (2014). Molecular diversity analysis of grape varieties based on iPBS markers. Biochemical Systematics and Ecology, 52, 27-32. https://doi.org/10.1016/j.bse.2013.10.008

Hammons, R.O. (1994). The origin and history of the groundnut. In: Smartt, J. (Ed.). The Groundnut Crop: A Scientific Basis for Improvement. London Chapman \& Hall, 24-42 p. ISBN 0412 408201. https://doi.org/10.1007/978-94011-0733-4

He, G., Prakash, C.S. (1997). Identification of polymorphic DNA markers in cultivated peanut (Arachis hypogaea L.). Euphytica, 97(2), 143-149.

He, G., Prakash, C. (2001). Evaluation of genetic relationships among botanical varieties of cultivated peanut (Arachis hypogaea L.) using AFLP markers. Genetic Resources and Crop Evolution, 48(4), 347-352. https://doi.org/10.1023/A:1012019600318

He, G., Meng, R., Gao, H., Guo, B., Gao, G., Newman, M., Pittman, R.N., Prakash, C.S. (2005). Simple sequence repeat markers for botanical varieties of cultivated peanut (Arachis hypogaea L.). Euphytica, 142(1-2), 131-136.

Jaccard, P. (1908). Nouvelles recherches sur la distribu-tion florale. Bull. Soc. Vaudoise Sci. Nat., 44(163), 223-270.

Naidu, R.A., Kimmins, F.M., Deom, C.M., Subrahmanyam, P., Chiyembekeza, A.J., van der Merwe, P.J.A. (1999). A Virus Disease Affecting Groundnut Production in Sub-Saharan Africa. Plant Disease, 83(8), 700-709.

Kalendar, R., Antonius, K., Smykal, P., Schulman, A.H. (2010). iPBS: a universal method for DNA fingerprinting and retrotransposon isolation. Theoretical and Applied Genetics, 121, 1419-1430. https://doi.org/10.1007/s00122-010-1398-2

Kalendar, R., Amenov, A., Daniyarov, A. (2019). Use of retrotransposon-derived genetic markers to analyse genomic variability in plants. Funct Plant Biol, 46(1), 15-29. https://doi.org/10.1071/FP18098

Krapovickas, A., Gregory, W.C. (1994). Taxonomy of the genus Arachis (Leguminosae). Bonplandia, 8, 1-186.

Kut'ka-Hlozáková, T., Gregová, E., Vivodík, M., Gálová, Z. 2016. Genetic diversity of European cultivars of common wheat (Triticum aestivum L.) based on RAPD and protein markers. Journal of Central European Agriculture, 17(4) 957-969. https://doi.org/10.5513/JCEA01/17.4.1798

Leal-Bertioli, S., Shirasawa, K., Abernathy, B., Moretzsohn, M., Chavarro, C., Clevenger, J., Ozias-Akins, P., Jackson, S., Bertioli, D. (2015). Tetrasomic recombination is surprisingly frequent in allotetraploid Arachis. Genetics, 199(4), 1093-1105. https://doi.org/10.1534/genetics.115.174607

Lessig, V.P. (1972). Comparing cluster analyses with cophenetic correlation. Journal of Marker Research, 9(1), 82-84.

Milovanov, A., Zvyagin, A., Daniyarov, A., Kalendar, R., Troshin, L. (2019) Genetic analysis of the grapevine genotypes of the Russian Vitis ampelographic collection using iPBS markers. Genetica, 147(1), 91-101. https://doi.org/10.1007/s10709-019-00055-5

Melnikova, N.V., Kudryavtseva, A.V., Speranskaya, A., Krinitsina, A.A., Dmitriev, A.A., Belenikin, M.S, Upelniek, P.U., Batrak, E.R., Kovaleva, I.S., Kudryavtsev, A.M. (2012). The FaRE1 LTR-retrotransposon Based SSAP Markers Reveal Genetic Polymorphism of Strawberry (Fragaria x ananassa) Cultivars. Journal of Agricultural Science, 4(11), https://doi.org/111-118. $\underline{10.5539 / j a s . v 4 n 11 \mathrm{p} 111}$

Mondal S., Badigannavar, A.M., Murty, G. S. S. (2007). RAPD markers linked to a rust resistance gene in cultivated groundnut (Arachis hypogaea L.). Euphytica, 159(1-2), 233-239. https://doi.org/10.1007/s10681-007-9482-7

Monden, Y., Yamaguchi, K., Tahara, M. (2014). Application of iPBS in highthroughput sequencing for the development of retrotransposon-based molecular markers. Current Plant Biology, 1, 40-44. https://doi.org/10.1016/j.cpb.2014.09.001

Moretzsohn, M.C., Gouvea, E.G., Inglis, P.W., Leal-Bertioli, S.C.M., Valls J.F.M., Bertioli, D.J. (2013). A study of the relationships of cultivated peanut (Arachis hypogaea) and its most closely related wild species using intron sequences and microsatellite markers. Annals of Botany, 111(1), 113-126.

Naidu, R.A., Kimmins, F.M., Deom, C.M., Subrahmanyam, P., Chiyeubekeza, A.J., van der Merwe, P.J.A. (1999). Groundnut rosette: a virus disease affecting groundnut production in sub-Saharan Africa. Plant Disease, 83(8), 700-709.

Nascimento, E.F.M.B., Santos, B.V., Marques, L.O.C., Guimarães, P.M., Brasileiro, A.C.M., Leal-Bertioli, S.C.M., Bertioli, D.J., Araujo, A.C.G. (2018) The genome structure of Arachis hypogaea (Linnaeus, 1753) and an induced Arachis allotetraploid revealed by molecular cytogenetics. Comparative Cytogenetics, $12(1)$

https://doi.org/10.3897/CompCytogen.v12i1.20334

Nielen, S., Campos-Fonseca, F., Leal-Bertioli, S., Guimarães, P., Seijo, G. Town, C., Arrial, R., Bertioli, D. (2010). FIDEL - a retrovirus-like retrotransposon and its distinct evolutionary histories in the A- and B-genome 
components of cultivated peanut. Chromosome Research, 18(2), 227-246. https://doi.org/10.1007/s10577-009-9109-z

Nielen, S, Vidigal, B.S., Leal-Bertioli, S.C.M., Ratnaparkhe, M., Paterson, A.H., Garsmeur, O., D’Hont, A., Guimarães, P.M., Bertioli, D.J. (2011). Matita, a new retroelement from peanut: characterization and evolutionary context in the light of the Arachis A-B genome divergence. Molecular Genetics and Genomics, 287(1), 21-38. https://doi.org/10.1007/s00438-011-0656-6

Pandey, M.K., Gautami, B., Jayakumar, T., Sriswathi, M., Upadhyaya, H.D., Gowda, M.V.C., Radhakrishnan, T., Bertioli, D.J., Knapp, S.J., Cook, D.R., Varshney, R.K. (2012). Highly informative genic and genomic SSR markers to facilitate molecular breeding in cultivated groundnut (Arachis hypogaea). Plant Breeding, 131(1), 139-147. https://doi.org/10.1111/j.1439-0523.2011.01911.x

Proite, K., Leal-Bertioli, S.C.M., Moretzsohn, M.C., Silva, F.R., Martins, N.F., Guimaraes, P.M. (2007). ESTS from a wild Arachis species for gene discovery and marker development. BMC Plant Biology, 7(1):7. https://doi.org/10.1186/1471-2229-7-7

Raina, S.N., Rani, V., Kojima, T., Ogihara, Y., Singh, K.P., Devarumath, R.M (2001). RAPD and ISSR fingerprints as useful genetic markers for analysis of genetic diversity, varietal identification, and phylogenetic relationships in peanut (Arachis hypogaea) cultivars and wild species. Genome, 44(5), 763-772.

Richards, C.M., Volk, G.M. (2010). New challenges for data management in $\begin{array}{llll}\text { genebanks. } & \text { Acta } & \text { Horticulturae, } & 859\end{array}$ https://doi.org/10.17660/ActaHortic.2010.859.39

Simpson, C.E., Krapovickas, A., Valls, J.F.M. (2001). History of Arachi including evidence of $A$. hypogaea L. Progenitors. Peanut Science, 28(2), 78-79. Song, G.Q., Li, M.J., Xiao, H., Wang, X.J., Tang, R.H., Xia, H. Zhao, C.Z., Bi, Y.P. (2010). EST sequencing and SSR marker development from cultivated peanut (Arachis hypogaea L.). Electronic Journal of Biotechnology, 13(3). https://doi.org/10.2225/vol13-issue3-fulltext-10

Smykal, P., Bacova-Kerteszova, N., Kalendar, R., Corander, J., Schulman, A.H., Pavelek, M. (2011). Genetic diversity of cultivated flax (Linum usitatissimum L.) germplasm assessed by retrotransposon-based markers. Theoretical and Appied. Genetics, 122(7), 1385-1397. https://doi.org/10.1007/s00122-011-1539-2

Stalker, H.T., Simpson, C.E. Germplasm resources in Arachis. In: Pattee, H.E., Stalker, H.T. (Eds.). (1995). Advances in Peanut Science. Stillwater. OK : American Peanut Research and Education Society, 14-53 p.

Stalker, H.T., Wilson, R.F. (eds). (2016). Peanuts. Genetics, processing and utilization. Academic Press and AOCS Press, ISBN 978-1-63067-038-2.

Valls, J.F.M., Simpson, C.E. (2005). New species of Arachis (Leguminosae) from Brazil, Paraguay and Bolivia. Bonplandia, 14(1/2), 35-63.

Vivodík, M., Balážová, Ž., Gálová, Z., Petrovičová, L. (2019). Start Codon Targeted Polymorphism for evaluation of functional genetic variation and relationships in cultivated castor (Ricinus communis L.) genotypes. Genetika, 51(1), 137 - 146. https://doi.org/10.2298/GENSR1901137V

Weber, J.L. (1990). Informativeness of human (dC-dA)n.(dG-dT)n polymorphisms. Genomics, 7(4), 524-30.

Žiarovská, J., Ražná, K., Fernandéz E.C., Bošel’ová, D., Kysel', M. (2019).

Habitat-related specifity of iPBS fingerprint in European populations of Hedera helix L. Folia Oecologica, 46(1), 30-36. 